\title{
CONTROLLING THE HOUSEHOLD ELECTRICITY LOAD THROUGH COMPUTERS AND SMARTPHONES
}

\author{
Syaiful Amri, Wenny Wahyuni
}

\begin{abstract}
Abstrak-Electricity consumption in the world is getting more massive with limited amount of fuel and its expensive price, not to mention the rising of electricity rates (the revocation of subsidy electricity). Therefore, it requires alternative solutions to tackle on energy crisis. One of the ways to save electrical energy is by turning off unutilized electrical appliances. Automation is highly required in daily lives especially in this modern age that demands more effectiveness and efficiency in daily activities. Oftentimes, one forgets about some tiny actions such as turning off the lamps dispenser, fans, air conditioners and any other electrical appliances. These actions cause electrical energy waster due to electricity consumption negligence. In order to avoid electrical energy waste, it requires an easy and effective electricity load control system. Relay Driver is utilized as an intermediary thus the main computer is able to control actuator with an on/off switch. Electrical appliances are able to be controlled over an application in an android smartphone as well as in a computer which are connected to internet through a wireless connection (WiFi) by tapping a menu feature in the application in order that it can be accessed automatically and can be controlled manually and borderlessly. The maximum range that can be detected by TP-Link Wireless N Router TL-WR841N is 75 meter.
\end{abstract}

Key Words-Bluetooth, WiFi, Computer control.

\section{INTRODUCTION}

E lectricity is highly vital energy for human's lives since almost all their daily activities are in need for electrical energy, from household works to industry. Almost all of the household appliances require electrical energy. Therefore, electrical energy can be categorized as the primary necessity since main human's activities require electrical energy as the driving force.

The need of electrical energy has been taking improvement along with economy growth. Meanwhile, electricity system development nowadays are no longer suitable for electricity need growth thus this causes electricity crisis. As the consequence, the electricity service provider regularly performs alternating blackout in certain regions. Several steps taken to resolve electrical energy crisis is certainly not only be carried

Syaiful Amri, lecture in Electrical Engineering-Engineering Deprt State Polytechnic of Bengkalis, Riau, Indonesia (email : syaifulamri@polbeng.ac.id)

Wenny Wahyuni, lecture in Electrical Engineering-Engineering Deprt State Polytechnic of Bengkalis, Riau, Indonesia (email : wennywahyuni@polbeng.ac.id out by the electricity provided but also by the electricity consumers. Specifically in this study, efficient electricity consumption from the consumer point of view is the most accurate step to tackle on electricity energy crisis. Several methods that can be engaged to improve the efficiency in electricity energy consumption for instance applying electricity saving tools, using electronic appliances that save electricity, and using energy saver lamps. Other than those methods, one method that is quite effective in saving electricity is by minimizing electricity consumption in the peak load.

Saving electricity energy consumption by reducing usage in the peak load can be performed by turning of electronic appliances in certain hour. However, people often turn off their electronic appliances in certain hour behind schedule, or even they forget to do so. Hence, it requires electronic appliances control system which are able to help people to turn off or on their appliances on time in certain hour.

\section{Metodology}

\section{A. Diagram Block}

MiniPC (mini size computer) was utilized as the main controller over electronic appliances. This computer is extremely easy to place as it is small. Besides, electricity energy needed to operate it was pretty ungenerous.

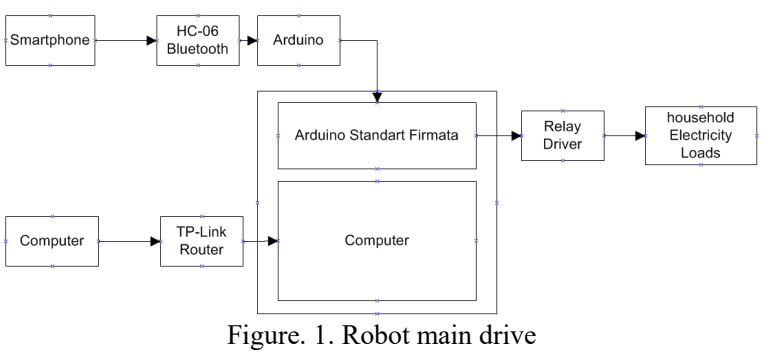

The component functions used in the Figure 1 diagram block were:

- Smartphone

Smartphone function as the interface which consisted of control menus and features to oversee the ongoing process. 
- Bluetooth HC-06

Additional device for data communication hardware from a smartphone to Arduino through Bluetooth.

- Computer

This computer was installed with a controller interface application as well from which later sent commands to the main computer through TP-Link Router WiFi.

- Controller Application

This application worked to read every command from a smartphone through a Bluetooth as well as from a computer through WiFi. After the command had been read, the next was this controller application sent logic 1 or 0 to the relay driver. The signal sent from a computer through a serial port was being communicated with Arduino into which was installed library standard firmata.

- Relay Board

In order miniPC was able to drive the electricity device, the relay board was required. This relay board forwarded every logic that was supplied by miniPC. The electricity loads in this study consisted of four pieces of AC lamps and a fan.

\section{B. Designing the Softwares}

There were couples of softwares created in this study; a software that was planted into the transmitter and a software that was planted into the receiver as the controller center which was in this case miniPC.

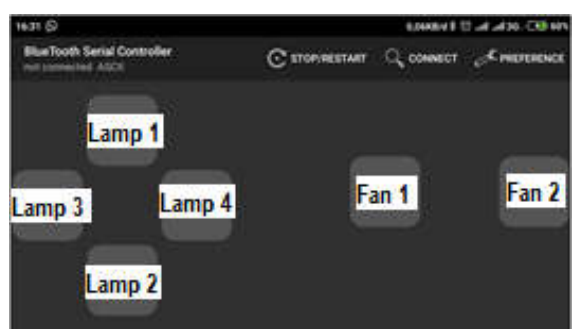

Figure. 2. Transmitter interface 1 in a smartphone

In Figure 2, it depicts interface in the transmitter which was planted in a smartphone as the user command interface that was going to be sent to the receiver (minPC) through a Bluetooth.

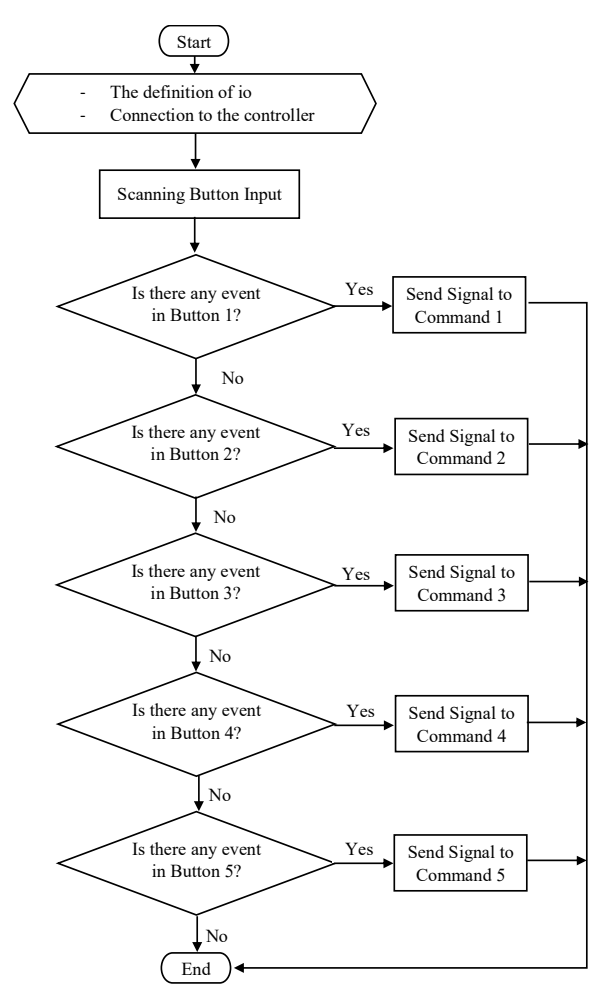

Figure. 3. Transmitter Algorithm

Figure 3 is a logic planted in the transmitter of smartphone as well as computer. Every time there was an event inflicted upon the button, it sent a command in a form of character to the receiver (miniPC) through Bluetooth as well as WiFi

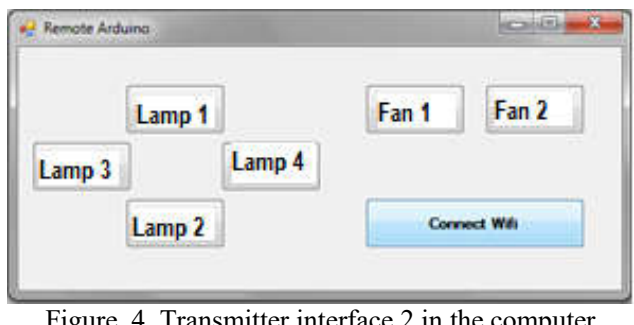

Figure 4 is an algorithm planted in the miniPC receiver. Computer performed input scanning in both serial and $\mathrm{WiFi}$ then sent command to drive the actuator in accordance with the command received.

In the main interface program, there were two input scanning commands. The first input was by receiving serial inputs sent through Arduino as the bridge between main computer with Bluetooth module HC06. While input scanning command through Wifi in this study used thread facility with C\# language

Computer controled the actuator (household appliances) which was by performing serial communication with Arduino that had been planted with library standard firmata hence io arduino could be accessed through an application in the main computer. 


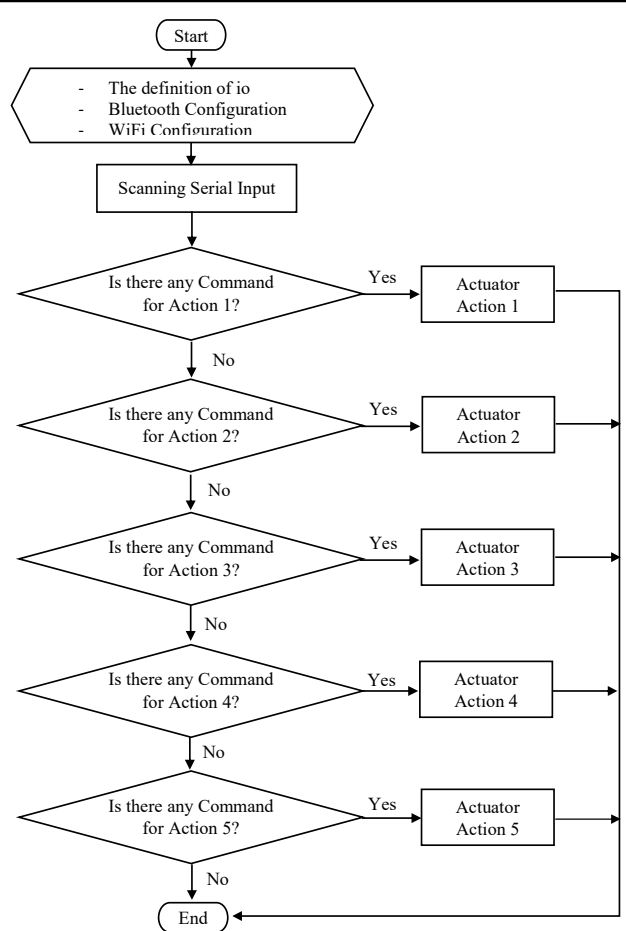

Figure. 5. Algorithm receiver in the main computer

\section{The Result of Household Miniature}

Designing house miniature aimed to obtain IoT control result through Bluetooth, WiFi, and computer.

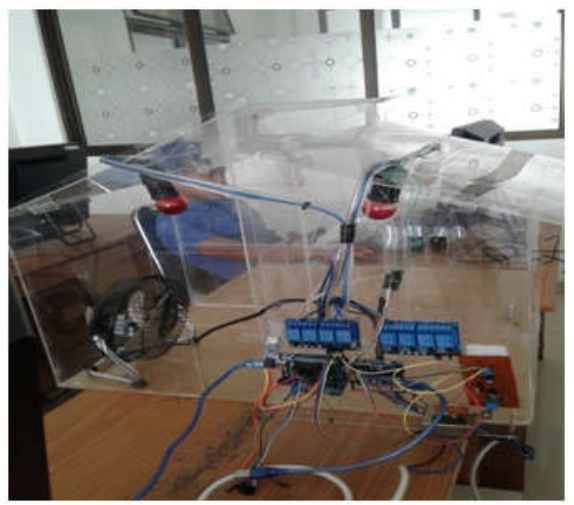

Figure. 6. Miniature result

\section{RESULT AND ANALYSIS}

\section{A. Testing the Controller Connection}

Class C IP address testing was performed by changing the host ID in IP address controller, while IP address in household miniature miniPC did not change. The number of changed host ID was 10 pieces which were performed randomly; the range was from 0 to 254 which if it was added together, it became 255 host ID. Class C IP address consisted of 24bit for network ID and the rest was 8 bit for host ID. Thus, Class C IP address host ID was commonly used for a small scale network.

Generally, by using Class C IP address, it simplified the implementation to perform testing on household miniature, hence the writer was able to create conclusion and analysis from the testing performed. Testing to change Class C IP address host ID can be viewed in Table 1 .

TABLE I CONNECTION TESTING

\begin{tabular}{lll}
\hline \multicolumn{3}{c}{ IP Address } \\
Controller & $\begin{array}{c}\text { Household Miniature } \\
\text { IP Address Mini PC }\end{array}$ & \multicolumn{1}{c}{ Connection } \\
\hline 192.168 .1 .0 & 192.168 .1 .100 & Success \\
192.168 .1 .0 & 192.168 .1 .100 & Success \\
192.168 .1 .0 & 192.168 .1 .100 & Success \\
192.168 .1 .0 & 192.168 .1 .100 & Success \\
192.168 .1 .0 & 192.168 .1 .100 & Success \\
192.168 .1 .0 & 192.168 .1 .100 & Success \\
192.168 .1 .0 & 192.168 .1 .100 & Success \\
192.168 .1 .0 & 192.168 .1 .100 & Success \\
192.168 .1 .0 & 192.168 .1 .100 & Success \\
192.168 .1 .0 & 192.168 .1 .100 & Success \\
& & \\
\hline \hline
\end{tabular}

\section{B. Testing the WiFi Range Distance}

After performing the testing on each component and system, entirety testing which was from the start to the end was performed. This entirety system testing was the last step in testing process on miniature household.

When household miniature was activated at the first time, controller data in PC/laptop was in charge of connecting the network to household miniature through connect button which was located in GUI data controller text box. After household miniature and PC/laptop data controller were already connected, then household miniature was prepared to be controlled by controller application from a smartphone through WiFi with computer GUI.

Based on the specification, reachable distance of TPTABLE II

TESTING THE CONNECTION RANGE

\begin{tabular}{cc}
\hline $\begin{array}{c}\text { Control Range } \\
\text { (Meter) }\end{array}$ & Testing Result \\
\hline 10 & Success \\
15 & Success \\
20 & Success \\
25 & Success \\
30 & Success \\
35 & Success \\
40 & Success \\
45 & Success \\
50 & Success \\
55 & Success \\
60 & Success \\
65 & Success \\
70 & Success \\
75 & Success \\
80 & Failed \\
85 & Failed \\
90 & Failed \\
95 & Failed \\
100 & Failed \\
\hline &
\end{tabular}

Link Wireless N Router TL-WR841N is $10-100$ meter. This testing was performed gradually with the first control distance of 10 meter. After the first testing was 
done, the control distance continued to be added by 5 meter that the next control distance touched 100 meter. This testing was performed by placing a barrier, which was mirror, between household and smartphone, and was performed without a barrier.

The result of control distance testing without a barrier can be viewed in Table 2 .

\section{CONCLUSION}

The maximum range that could be detected by TPLink Wireless N Router TL-WR841N was 75 meter while based on TP-Link Wireless N Router TLWR841N specification, the reachable distance of that router is $10-100$ meter.

\section{REFERENCES}

[1] Ashton K. 2009. That 'internet of things' thing. RFiD J. 22(7):97-114. Barbaran. Anbarasi A, and Ishwarya M. 2013. Desain and implementation of smart home using sensor network International Conference on Optical .

[2] Berlo A. V, Bob A, Jan E,Klaus F, Maik H, \& Charles W. 1999. Design Guidelines on Smart Homes, A COST 219bis Guidebook. Brussels, Belgium: Eur. Commission.

[3] Chen W. 2011. Application of internet of things for electric fire control. Electrical and Control Engineering (ICECE). hlm 47414743.

[4] X. Peng, M. Bessho, N. Koshizuka, and K. Sakamura, A framework for peak electricity demand control utilizing constraint programing method in smart building, in 2014 IEEE 3rd Global Conference on Consumer Electronics (GCCE), 2014, pp. 744-748.

[5] Liandana M, Putra M.A.W,Sistem Otomatisasi Rumah untuk Mengatur Perangkat Listrik pada Saat Beban Puncak. Konferensi Nasional Sistem \& Informatika, 2015. 